\title{
Conceiving Meteorology as the exact science of the atmosphere: Vilhelm Bjerknes's paper of 1904 as a milestone
}

\author{
GABRIELE GRAMELSBERGER*
}

Institute of Philosophy, Free University Berlin, Germany

\begin{abstract}
In January 1904 the Norwegian physicist Vilhelm Bjerknes published his seminal paper "Das Problem der Wettervorhersage, betrachtet von Standpunkt der Mechanik und Physik" in the Meteorologische Zeitschrift. Over seven pages Bjerknes developed the idea of a mathematical model of the atmosphere's dynamics based solely on physical and mechanical laws. Although his model was less practicable in those days, so that his concept was slow to $\mathrm{f}$ nd acceptance in the f eld of meteorology, we know today that the idea was revolutionary nonetheless.
\end{abstract}

\section{Zusammenfassung}

In der Januar Ausgabe der Meteorologischen Zeitschrift von 1904 veröffentlichte der Norwegische Physiker Vilhelm Bjerknes einen Artikel über "Das Problem der Wettervorhersage, betrachtet von Standpunkt der Mechanik und Physik". Auf nur sieben Seiten entwickelte Bjerknes ein dynamisches Modell der Atmosphäre basierend auf physikalischen und mechanischen Gesetzen. Obwohl die Anwendbarkeit seines Konzepts Anfang des 20. Jahrhunderts nicht gegeben war und es daher nur langsam Aufnahme in die Meteorologie fand, war seine Idee eines solchen Modells wegweisend.

\section{Introduction}

During the nineteenth century, interest in the general circulation of the atmosphere gained ground in meteorology. Studying the tropical wind systems, Edmond Halley had explained their dynamics as a result of solar heating (HALLEY, 1686), while George Hadley had added the earth's rotation as a basic factor (HADLEY, 1735). Referring to both theories Heinrich Wilhelm Dove developed his law of turning (Drehungsgesetz), claiming that all local winds are minor eddies of the alternating polar and equatorial wind fows (DOVE, 1837). However, the differential heating and rotation could not fully explain wind patterns. Another force was needed to explain meridional and zonal wind fows when William Ferrel rediscovered the Coriolis force and applied it to the atmosphere (FERREL, 1858). "With this 'new force' taken into account, the earth's atmosphere generated three circulation cells and oblique wind in mid-latitudes with high velocities from the west. Moreover, high pressure at the poles which would be expected because of low temperature was reversed to low pressure by the excessive centrifugal force of the whirling winds. Conversely, high pressure was generated near the tropics. Ferrel's theoretical results, which Cleveland Abbe called the principia meteorologica, were in accordance with the latest observations" (quoted from FLEMMING, 2002, p. 210). Ferrel's work inaugurated what became known as dynamical meteorology.

\footnotetext{
*Corresponding author: Gabriele Gramelsberger, Free University Berlin, Institute of Philosophy, Dept. of Philosophy and Humanities, Habelschwerdter Allee 30, 14195 Berlin, e-mail:gab@zedat.fu-berlin.de
}

Parallel to this development the dynamic of the atmosphere became a topic of hydrodynamics, although this f eld "had turned into a subject matter for mathematicians and theoretical physicists" (quoted from ECKERT, 2006, p. 25) during the nineteenth century by virtue of its focus on idealised fuids. In 1755 Leonhard Euler had described the general equations of motion in inviscid f uids (Euler, 1755), which Claude L. Navier expanded for viscous ones (NAVIER, 1822). In 1845 George G. Stokes reformulated these equations, now known as the Navier-Stokes equations, by employing a method that "does not necessarily require the consideration of ultimate molecules [as Navier did]. Its principle feature consists in eliminating from the relative motion of the fuid about any particular point the relative motion which corresponds to a certain motion of rotation, and examining the nature of the relative motion which remains" (quoted from STOKES, 1880a, p. 185; STOKES, 1880b). Stokes derived some applicable results by analysing his equations, e.g. for the velocity prof le of a f uid in a tube, but hydrodynamics remained a highly abstract discipline. The most problematic aspect of idealised fuids was the conclusion that no vortices could occur, as vorticity was conceived as friction between particles. Although Hermann von Helmholtz showed in 1858 that vortices can persist in idealised f uids, he was forced to claim that they can not be created or destroyed in such f uids (HELMHOLTZ, 1858).

Applying hydrodynamics to the atmosphere requires explaining both the appearance and disappearance of vortices as well as the transition from laminar to turbulent fow, as Osborne Reynolds demonstrated in the 1870 s by studying this phenomena using coloured wa- 
ter (REYNOLDS, 1900). It was Helmholtz's claim about vorticity and his assumption that density depends solely on pressure in an idealised f uid that evoked Vilhelm Bjerknes' interest in the 1890s and inspired him to articulate the "generalised circulation theorem". "He hoped to derive equations that would be independent of the specif $\mathrm{c}$ shape of the bodies and to consider situations analogous to various electromagnetic phenomena. Diff culties ensued. Attractive and repulsive phenomena between the fuid bodies seemed to occur with an accompanying production of vortices in the boundary layer between the fuid bodies and the surrounding f uid. This result contradicted the well-established theorems of Helmholtz and Lord Kelvin which claimed vortex motions and circulations in frictionless, incompressible fuids are conserved" (quoted from FRIEDMAN, 1989, p. 19). Questioning the simplifying assumptions, Bjerknes realised that density in a heterogeneous f uid without any restrictions on compressibility depends not only on pressure, as in the concepts of Helmholtz and Kelvin, but on other variables as well. In other words: There could be various reasons for circulation in a heterogeneous fuid. In particular, Bjerknes' geometrical model of circulation claimed that pressure and density intersecting in a threedimensional surface would form a series of tubes he called solenoids. The number of solenoids encompassing the fuid curve would determine the rate of increase of circulation. When pressure and density coincide, no solenoids exist and circulation remains invariable with time (THORPE et al., 2003).

Bjerknes' generalised circulation theorem immediately provoked the interest of meteorologists like Nils Ekholm and Svante Arrhenius when he presented his theory at the Stockholm Physics Society in March 1897, and again in February 1898, on the latter occasion with some references to the mechanics of the atmosphere (BJERKNES, V., 1898). In particular, Ekholm's interest in a theory of cyclones - he had realised that in the vicinity of a cyclone pressure and density do not always coincide (EKHOLM, 1891) - pointed the way to a fruitful application of Bjerknes' theorem in meteorology. Soon after the theorem began circulating in the international meteorological community Bjerknes was asked to publish his ideas in the Meteorologische Zeitschrift and in Monthly Weather Review, both in 1900, followed by his seminal paper in 1904 (BJERKNES, V., 1900a, b, 1904).

\section{Biographical notes about Vilhelm Bjerknes}

Vilhelm Bjerknes was born in Christiania (now Oslo), Norway (14 March 1862 - 9 April 1951). His father Carl Anton Bjerknes was a professor in applied mathematics at the Royal Frederik University in Christiania with a strong interest in hydrodynamics. Together with his father, after completing his studies in physics, Bjerknes worked on hydrodynamical analogies to explain electrodynamics. In 1890 and 1891 he worked as an assistant to physicist Heinrich Hertz and in 1895 he was appointed professor of applied mechanics and mathematical physics at the University of Stockholm. Bjerknes moved to Norway in 1907 after the country became independent of Sweden in 1905.

Although since the 1890s Bjerknes had pursued the goal of making a substantial contribution to physics by developing a "general circulation theorem", he realised that he could not resist "getting sucked into the meteorological vortex", as Robert Friedman related in Bjerknes' own words in his remarkable study Appropriating the Weather: Vilhelm Bjerknes and the Construction of a Modern Meteorology (FRIEDMAN, 1989; BJERKNES, V., 1898, 1910/1911). The rise of interest in cyclone development paved the way for Bjerknes' general circulation theorem in meteorology. In 1900 he was asked by Julius Hann (Editor of Meteorologische Zeitschrift) and Cleveland Abbe (Editor of Monthly Weather Review) to publish his ideas (BJERKNES, V., 1900a, b). From this point on he began to seriously consider a research program of an exact science of the atmosphere based on the laws of physics, to be pursued together with his students Johan W. Sandström and Vagn W. Ekman. When a series of storms moved over Sweden in 1902 and 1903, a campaign for a storm-warning system was launched by Nils Ekholm, with Bjerknes contributing a talk at the Stockholm Physics Society in October 1903 on a rational method for weather prediction to the discussion. He explained his weather prediction ideas comprehensively in the seminal 1904 paper in Meteorologische Zeitschrift, but actually realising such a research program required funding. In 1906, after a talk at the Columbia University in December 1905, Bjerknes received f nancial assistance from the Carnegie Institute of Washington to employ Sandström on his project: the development of methods to apply mechanical physics to the atmosphere and the ocean. Together with Sandström he published the project's results in the volumes of Dynamic Meteorology and Hydrography (BJERKNES, V. and SANDSTRÖM, 1910/1911) and popularized his methods in a series of lectures at the Royal Meteorological Society in London and the Berlin Society for Aeronautics.

Bjerknes' shift from physics to meteorology led him to the University of Leipzig. Leipzig had become a centre for aeronautics with a giant Zeppelin airship hangar. In January 1913 he was appointed professor of geophysics and director of the newly founded Leipzig Geophysical Institute. There Bjerknes tried to establish his theoretical program of numerical weather forecasting. Working with his assistant Robert Wenger and the Carnegie assistants Harald U. Sverdrup, Theodore Hesselberg and Johan Holtsmark he produced several studies, including papers on the inf uence of mountains on the motion of air, thermal inversion, a scale theory for atmospheric motions, and other topics (cf. FRIEDMAN, 1989, 
p. $91 \mathrm{ff})$. Together with his doctoral student Herbert Petzold he investigated the connection between lines of convergence and line squalls as a contribution to Richard Assmann's line-squall warning system.

In summer 1917 Bjerknes returned to Norway. He had received a call to the Bergen museum to found the Bergen Geophysical Institute. Although he tried to resume the Leipzig research program of numerical weather forecasting, his activities shifted from theoretical to more practical research due to the entirely different situation in Bergen. The lack of a dense network of observational stations in Norway propelled Bjerknes into the business of storm and rain warnings as a service for f shery and agricultural production. In 1918 Bjerknes and others set up an experimental weather service and Bjerknes' son Jacob began studying the relation between lines of convergence and cyclones (BJERKNES, J., 1919). During this period Bjerknes gave up the purely theoretical and numerical approach he had pursued in Leipzig. Instead, he shifted towards a qualitative approach, studying the formation of clouds as indicators for upper-air currents and thus introducing a new cyclone model and a new way of weather forecasting (BJerknes, V., 1920). During the following years Bjerknes, his son Jacob and his assistants developed the frontal theory and laid down the foundation of the now renowned Bergen School (BJERKNES, J. and SOLBERG, 1922). In 1926 Bjerknes returned to the University of Oslo until his retirement in 1932.

\section{The 1904 paper in Meteorologische Zeitschrift}

The 1904 paper by Vilhelm Bjerknes is rooted in his work as a physicist on generalising hydrodynamic action-at-a-distance, which he had published in 1900 in the Meteorologische Zeitschrift and in Monthly Weather Review (BJERKNES, V., 1900a, b). In this paper he had outlined the geometrical and physical ideas of his general circulation theorem to the meteorological community, encouraged by Cleveland Abbe and Julius Hann. In response to heavy storms in 1902 and 1903 Bjerknes developed his theoretical ideas further and presented them as "A Rational Method for Weather Prediction" at a meeting of the Stockholm Physics Society in October 1903 (BJERKNES, V., 1903). In opposition to purely empirical and statistical methods, Bjerknes presented his rational version of forecasting based on the laws of mechanics and physics of the atmosphere. This approach prompted him to introduce the concept in a 1904 paper entitled "Das Problem der Wettervorhersage, betrachtet von Standpunkt der Mechanik und Physik". It is worth mentioning that Bjerknes described his mathematical concept over seven pages without a single formula. Nevertheless his concept outlined the foundation of a weather forecasting model.
The 1904 paper is divided in six sections, dealing with the diagnosis of the current state of the atmosphere (I), the introduction of the laws of mechanics and physics of the atmosphere and the resulting equations (II), some considerations on how to integrate the seven equations (III), a precise proposal for a general computing scheme by decomposing the main problem into partial problems (IV), a discussion of the computation of the prognostic equations taking into account the lack of knowledge about air resistance and other factors (V), and considerations about the resolution of initial data based on observation (VI). Within these sections Bjerknes developed his method to "construct the pictures of the future states of the atmosphere from the current state of the atmosphere at a starting point" (cf. VI) following the deterministic approach of physics as celestial mechanics, best articulated by Pierre de Laplace in 1820: "We ought to regard the present state of the universe as the effect of its antecedent state and as the cause of the state that is to follow" (LAPLACE, 1951: Preface). Unlike Laplace, Bjerknes had to deal with a system that was rather more complex than celestial mechanics. Therefore he was aware of simplif cations, for instance the lack of evaporation in his model (cf. II) and the problem of turbulence (cf. V). However, the origin of Bjerknes' concept is deeply rooted in $19^{\text {th }}$-century physics.

The 1904 paper conceived a mathematical model of the atmosphere based on the three hydrodynamic equations of motion, the continuity equation, the equation of the state of the atmosphere, and the f rst and (today unusual) second fundamental theorem in the mechanical theory of heat. But the paper also sketched the entire program needed for rational weather forecasting, combining theory and observation. As outlined in the biographical notes, it was Bjerknes' desire to realize his rational method of forecasting beyond mere theoretical considerations. He was deeply convinced that reliable forecasts could be achieved only if meteorology would become an exact science of the atmosphere. Of course he was not the only one who dreamt about atmospheric science. Since Ferrel at the latest, the treatment of the atmosphere's motion on the basis of physical laws, known as dynamical meteorology, had been on the meteorological agenda (FERREL, 1858). Proponents like William N. Shaw, Cleveland Abbe, Max Margules, Felix Exner, and others called for meteorology as a discipline of applied physics that explained observational data deductively. Even back in 1890 Abbe had complained that "the professional meteorologist has too frequently been only an observer, a statistician, an empiricist - rather than a mechanician, mathematician and physicist" (Abbe quoted from NEBEKER, 1995, p. 28). However, Bjerknes had a profound interest in setting up an extensive program to make this happen, involving regular and unif ed observations, an applicable model built on the laws of physics, and an effective method of computing. Because neither an analytical solution nor direct numerical integration 
of the equations, a project Lewis F. Richardson took on two decades later (RICHARDSON, 1922), were achievable, Bjerknes proposed (cf. VI) and, during the following years, developed a graphical method recasting mathematical operations into graphical ones.

The efforts of Bjerknes and his assistants, in particular Johan W. Sandström, to realize the program outlined in 1904 led to the 1910 Statics and the 1911 Kinematics volume of Dynamic Meteorology and Hydrography (BJERKNES, V. and SANDSTRÖM, 1910/1911). The importance of a graphical algebra was highlighted in chapter eight. "The development of proper graphical methods for performing these operations directly upon the charts will be of the same importance for the progress of dynamic meteorology and hydrography as the methods of graphical statistics and of graphical dynamics have been for the progress of technical sciences" (quoted from BJERKNES, V. and SANDSTRÖM, 1910/1911, p. 69). This fruitful collaboration was continued when Bjerknes became director of the Leipzig Geophysical Institute from 1913 until 1917. In his inaugural lecture at Leipzig he claimed that "there is only one task: to compute future states of the atmosphere", continuing conf dently: "If the weather of a single day could be computed during years of work, a scientif c victory of enormity would be gained" (quoted and translated from BJERKNES, V., 1913 , p. 14, 16). It must be considered that in the beginning of the $20^{\text {th }}$ century computing schemes were by no means familiar scientif c products (GRIER, 2005); neither were vertical measurements mere routine. The straposphere was just being discovered by Léon Teisserence de Bort, Richard Assmann and others; electronic computing machines would not be built for another forty years, and Lewis Fry Richardson had not begun to think about Weather Prediction by Numerical Processes (RICHARDSON, 1922).

\section{Discussion}

Although Bjerknes' presuppositions, e.g. of a "complete diagnosis of the state of the atmosphere" (cf. I) and that the "hydrodynamical partial problem will not pose any major mathematical diff culties" (cf. V), were fairly optimistic, he was bound and determined to realize his program as a required contribution to meteorology. "Bjerknes's goal was to alter the nature of meteorology, including aerology. [...] He noted that considerable sums were spent on meteorology (and oceanography) around the world with little effect, and for lack of 'any leading idea, or any tendency to take into application the "intrinsic" laws of atmospheric or oceanic processes, we fully know" (quoted from FRIEDMANN, 1989, p. 61). Therefore he started popularizing his ideas throughout the meteorological communities of Scandinavia, Germany, Great Britain and the United States. Supported by the Carnegie Institute of Washington from 1906 on and as director of the Leipzig Geophysical Institute from
1913 until 1917 he had the opportunity to implement his rational weather forecast program. In his book on Calculating the Weather Ferderik Nebeker evaluated Bjerknes' program, "which if successful would have united the three traditions, gained the attention and applause of meteorologists everywhere, but progress was slow" (quoted from NEBEKER, 1995, p. 2). World War I and, from 1917 on, the practical requirements in Bergen constrained his efforts. In Bergen the increasing shift from atmospheric variables to weather phenomena introduced another revolution to meteorology, known today as the "Bergen School".

Bjerknes' f rst revolution of 1904 f nally took hold when weather observation had improved considerably, so that Jules Charney et al. were able to compute the very $\mathrm{f}$ rst weather model on ENIAC in 1950 (CHARNEY et al., 1950) and the era of numerical weather forecasting began. However, Bjerknes' concept did not appear from nowhere. It was rooted both in classical physics and in dynamical meteorology, the latter a fragmented f eld of research at that time. William N. Shaw, for instance, was well trained in mathematics and experienced in deriving equations from physical laws for meteorological problems. Julius Hann had used thermodynamics to explain warm dry winds from the Alps back in 1866. "In 1895 J.R. Schütz, a German physicist working at the University of Göttingen, extended Helmholtz's vorticity equations to the case of a compressible fuid. [...] In 1896 Ludwik Silberstein, a Polish physicist born in Warsaw, used Schütz's extension of Helmholtz's vorticity equations to consider the cause of emergence of rotation in a non-homogeneous fuid that initially has no such rotation. He considered a gas in which pressure and density surfaces may not coincide, which of course is the case in the atmosphere" (quoted from THORPE et al., 2003, p. 472-473). In 1901 Max Margules calculated the change of pressure within columns of differing temperature (MARGULES, 1901) and in 1902 Felix Exner computed a prognosis of air pressure (EXNER, 1902, 1908). However, the outstanding achievement of Bjerknes was the consolidation of the fragmented f eld of dynamic meteorology on a sustainable basis of theoretical, practical and computational research.

\section{Acknowledgments}

\section{References}

BJerknes, J., 1919: On the Structure of Moving Cyclones. - Mon. Wea. Rev. 47, 95-99.

Bjerknes, J., H. Solberg, 1922: The life cycle of cyclones and the polar front theory of atmospheric circulation. - Kristiana, Geofysiske Publikationer 3, 3-18.

BJERKNES, V., 1898: Über einen hydrodynamischen Fundamentalsatz und seine Anwendung besonders auf die Mechanik der Atmosphäre und des Weltmeeres. - Kongl. Sven. Vetensk. Akad. Handlingar 31, 1-35. 
—, 1900a: Das dynamische Princip der Cirkulationsbewegung in der Atmosphäre. - Meteorol. Z. 17, 97-106 and continued in Meteorol. Z. 17, 145-156.

—, 1900b: The Dynamic principles of the circulatory movements in the atmosphere. - Mon. Wea. Rev. 28, 434-443.

—, 1904: Das Problem der Wettervorhersage, betrachtet von Standpunkt der Mechanik und Physik. - Meteorol. Z. 21, $1-7$.

—, 1913: Die Meteorologie als exakte Wissenschaft. - (Inaugural Lecture held on January 8, 1913), Vieweg, Braunschweig.

—, 1914: Meteorology as an exact science. - Mon. Wea. Rev. 42, 11-14.

—, 1920: The Structure of the Atmosphere When Rain is Falling. - Quart. J. Roy. Meteor. Soc. 26, 140-199.

_, 1921: On the Dynamics of the Circular Vortex with Applications to the Atmosphere and to Atmospheric Vortex and Wave Motion. - Kristiana, Geophysiske Publikationer 2, 1-81.

BJERKneS, V., J.W. SAndström, 1910/1911: Dynamic Meteorology and Hydrography. - Carnegie Institution of Washington, Washington, D.C.

Charney, J., J. Fjortof, J. von Neumann, 1950: Numerical Integration of the Barotropic Vorticity Equation. Tellus 2, 237-254.

Dove, H.W., 1837: Meteorologische Untersuchungen. Berlin, Verlag der Sander'schen Buchhandlung.

ECKert, M., 2006: The Dawn of Fluid Dynamics. A Discipline between Science and Technology. - Weinheim, Wiley-VCH.

EKHOLM, N., 1891: Etude des conditions météorologiques à l'aide des cartes synoptiques représentants la densité de l'air. - Kongl. Sven. Vetensk. Akad. Handlingar 16, 14-15.

EXNER, F., 1902: Versuch einer Berechnung der Luftdruckveränderung von einem Tag zum nächsten. - Sitz.-Ber. Wiener Akad. Wiss. 111, 707-725.

—, 1908: Über eine erste Annäherung zur Vorausberechnung synoptischer Wetterkarten. - Metorol. Z. 25, 57-67.

EULER, L., 1755: Principes généraux du mouvement des f uides. II. Opera mathematica, Vol. 12. - Basel, Birkhäuser, 1954, 54-91.

FERREL, W., 1858: The inf uence of the Earth's rotation upon the relative motion of bodies near its surface. - Astron. J. 109, Vol V., 97-100.
FLEMMing , J.R., 2002: History of Meteorology. - A History of Modern Science and Mathematics, Vol. 3. - Biagre, B.S. (Ed.), New York, Scribner's, 184-217.

Friedman, R.M., 1989: Appropriating the Weather. Vilhelm Bjerknes and the Construction of a Modern Meteorology. - Ithaca, London, Cornell University Press.

GRIER, D.A., 2005: When Computers were Human. Princeton University Press, Princeton.

HadLey, G., 1735: The cause of the general Trade-Wind. Philos. T. R. Soc. Lond. 29, 58-62.

Halley, E., 1686: An historical account of the Trade-Winds and Monsoons observable in the seas between and near the Tropick, with an attempt to assign the physical cause of said Winds. - Philos. T. R. Soc. Lond. 16, 153-168.

Helmholtz, H.V., 1858: Über Integrale der hydrodynamischen Gleichungen, welche der Wirbelbewegung entsprechen. - CRELLE Journal für reine und angewandte Mathematik 55, 25-55.

LAPlace, P.-S. DE, 1951: A Philosophical Essay on Probabilities. - (Théorie analytique des probabiliés, Paris 1820) New York, Dover.

Margules, M., 1901: Über den Arbeitswert einer Luftdruckverteilung und die Erhaltung der Druckunterschiede. - Anzeiger der Kasierl. Akad. D. Wiss., Vienna 18, 194.

NAVIER, C.L., 1822: Memoire sur les lois du mouvement des f uides. - Mem. Acad. Sci. Inst. France 6, 389-440.

NeBEKER, F., 1995: Calculating the Weather. Meteorology in the 20th Century. - San Diego, Academic Press.

Reynolds, O., 1900: On Vortex Motion. - Papers on Mechanical and Physical Subjects (1977), Vol.1. - Cambridge, Cambridge Univ. Press, 184-192.

RichaRdsON, L.F., 1922: Weather Prediction by Numerical Processes. - Cambridge University Press, Cambridge.

StOKes, G., 1880a: On the theories of the internal friction of fuids in motion (1845). - Mathematical and Physical Papers, Vol. I, Cambridge, Cambridge Univ. Press., 75115.

- 1880b: Report on recent researches in hydrodynamics (1846). - Mathematical and Physical Papers, Vol. I, Cambridge, Cambridge Univ. Press, 157-187.

Thorpe, A., H. Volkert, M.J. Ziemianski, 2003: The Bjerknes' Circulation Theorem. A Historical Perspective. - Bull. Amer. Meteor. Soc. 84, 471-480. 